\title{
Arterial blood gases predict long-term prognosis in stage I non-small cell lung cancer patients
}

\author{
Shinjiro Mizuguchi", Takashi Iwata, Nobuhiro Izumi, Takuma Tsukioka, Shoji Hanada, Hiroaki Komatsu \\ and Noritoshi Nishiyama
}

\begin{abstract}
Background: Preoperative hypercapnia and hypoxemia are reportedly risk factors for postoperative complications. This study aimed to establish the long-term survival risk associated with abnormal preoperative arterial blood gases (ABGs) in patients with non-small cell lung cancer (NSCLC).

Methods: This study involved 414 patients with stage I NSCLC who underwent lobectomy/bilobectomy with mediastinal lymph node dissection. The patients were divided into groups with normal $(n=269)$ and abnormal $(n=145)$ ABGs.

Results: The patients in the normal ABG group (median age 67 years) were significantly younger than those in the abnormal ABG group (median age 70 years). There were no significant differences between the groups in gender, performance status, pathological stage, histology, postoperative complications, or preoperative comorbidity, except for chronic obstructive pulmonary disease/pulmonary fibrosis. The 3-, 5- and 10-year survival rates in the normal and abnormal ABG groups were 87,77 and 56 , and 78,63 and $42 \%$, respectively $(p=0.006$ ). According to multivariate analysis, age, gender, performance status, non-adenocarcinoma, differentiation of resected tumor, pathological stage, any prior tumor and abnormal ABGs (risk ratio, 1.61) were independent prognostic factors.
\end{abstract}

Conclusions: Abnormal ABGs predict long-term survival risk in patients with NSCLC, which is important for planning therapeutic strategies.

Keywords: Arterial blood gas, Prognosis, Lung cancer, Early stage

\section{Background}

Surgery is the most effective therapy for early non-small cell lung cancer (NSCLC). Indeed, the 5-year survival rates in patients who underwent pulmonary resection were as follows: clinical stage IA, $82.0 \%(n=6295)$; pathological stage IA $86.8 \%(n=4978)$; clinical stage IB, $66.8 \%(n=2339)$; and pathological stage IB $73.9 \%(n=2552)$ [1]. The 5and 10-year survival rates of 799 patients with screening-detected clinical stage I lung cancer who did not undergo surgical treatment were only 16.6 and $7.4 \%$, respectively [2]. A recent study of Japanese patients with operable cancer who elected to undergo

\footnotetext{
* Correspondence: m1293795@msic.med.osaka-cu.ac.jp Department of Thoracic Surgery, Osaka City University Hospital, 1-4-3 Asahimachi, Abeno-ku, Osaka 545-8585, Japan
}

stereotactic ablative radiotherapy reported 5 -year overall survival rates of 72 and $62 \%$ for stage IA and IB subgroups, respectively [3]. Therefore, anatomical lobectomy is performed in most cases, which is acceptable from a physiological point of view.

Prior to surgical treatment, oncological and physiological tolerance of the proposed procedure should be considered. To assess physiological tolerance, cardiopulmonary function evaluation, including general respiratory function tests, arterial blood gas (ABG) analysis, electrocardiography, and echocardiography, is important according to two recent sets of guidelines $[4,5]$. According to a review of preoperative evaluation of lung cancer resection candidates, active smoking, dyspnea, age, proposed extent of surgery, and presence of vascular disease, diabetes mellitus and dysrhythmia are variably associated with 
increased risks of complications and/or mortality [6]. One study reported that $37 \%$ of individuals who present with anatomically resectable disease are deemed unsuitable for surgery on the basis of poor pulmonary function alone [7]. Moreover, physiological variables have recently been shown to influence not only perioperative outcomes, but also long-term quality of life and survival after pulmonary resection in patients with NSCLC. Quality of life, particularly as it is related to physical function, such as forced expiratory volume in $1 \mathrm{~s}\left(\mathrm{FEV}_{1.0}\right)$ and diffusion capacity of the lungs for $\mathrm{CO}\left(\mathrm{DL}_{\mathrm{CO}}\right)[8-10]$, is affected after surgical resection.

ABG tests have also been used to evaluate pulmonary function before thoracic surgery to prevent subsequent respiratory insufficiency. Historically, hypercapnia (partial pressure of $\mathrm{CO}_{2}$ in arterial blood $\left[\mathrm{PaCO}_{2}\right]>45$ Torr) has been considered an exclusion criterion for pulmonary resection [11, 12]. Hypercapnia and hypoxemia $(<60$ Torr partial pressure of $\mathrm{O}_{2}$ in arterial blood $\left[\mathrm{PaO}_{2}\right]$ or $<90 \%$ oxygen saturation $\left[\mathrm{SaO}_{2}\right]$ ) are reportedly risk factors for postoperative complications [5]. However, according to British Thoracic Society guidelines, hypercapnia alone is not a predictor of complications after lung resection. Such patients are often precluded because of other adverse factors, such as postoperative $\mathrm{FEV}_{1.0}$ and $\mathrm{DL}_{\mathrm{CO}}<40 \%$ [13].

It has not been reliably established whether preoperative abnormal ABGs, such as low oxygenation, hypercapnia or hypocapnia, are predictors of prognosis in patients who undergo pulmonary resection. The hypothesis of this study is that abnormal ABG parameters are independently associated with a higher risk of longterm mortality, especially non-cancer related mortality. Given that the outcomes are not biased by organ failure caused by tumor compression or involvement, this study aimed to examine the correlation between preoperative ABG analysis and long-term risk of death in patients with stage I NSCLC.

\section{Methods}

\section{Patients}

The medical records of 587 continuous patients who underwent pulmonary resection for pathological stage I NSCLC at Osaka City University Hospital, from January 1998 to December 2012, were analyzed retrospectively. The following patients were excluded from the analysis: those who underwent partial/wedge resection, without radical mediastinal lymph node dissection (R0) as previously described [14], and those who underwent neoadjuvant therapy for lung cancer. Ultimately, the records of 414 patients with pathological stage I NSCLC who underwent lobectomy/bilobectomy with R0 were examined. Surgery was performed through an axillary mini-thoracotomy (assisted by video) or posterolateral thoracotomy (when extended lobectomy, e.g., chest wall resection, pulmonary arterioplasty or bronchoplasty was necessary). Histological classification was performed according to the World Health Organization criteria for histological typing of lung tumors [15]. Postoperative staging was based on the international TNM classification for lung cancer [16, 17]. Patients were followed at 1-6-month intervals postoperatively. Follow-up evaluation included physical examination, chest X-ray, and blood examination, including for tumor markers. Chest, brain and abdominal computed tomography were performed at 3-6-month intervals. Bone scanning was not routinely performed in asymptomatic patients. Whenever any symptoms or signs of recurrence were detected, magnetic resonance imaging of the brain and bone scintigraphy was performed. The patients $(\mathrm{n}=53 / 191 ; 28 \%)$ with stage $1 \mathrm{~A}$ (T1b) and 1B adenocarcinoma received oral fluoropyrimidine for 2 years. Dose escalation or schedule modification occurred at the discretion of the clinician. Patients underwent chemotherapy, radiotherapy, or the best available supportive care when recurrence was detected. The study was performed in accordance with the Declaration of Helsinki and received approval from the Institutional Review Board of the Osaka City University (Osaka, Japan, reference number 2793) with waiver of informed consent because of its retrospective design.

\section{Data collection and follow-up evaluation}

The patients' demographic data, surgical outcomes, and complications were reviewed, and the survival rate was analyzed. Follow-up results and causes of death were obtained from patients' medical records (in our institute and with their practitioners/pulmonologists) and telephone calls, and the last follow-up day was June 30, 2015.

In-hospital mortality included all deaths during the first 30 days or postoperative hospital stay. Postoperative complications were classified as major (potentially lifethreatening) or minor (not life-threatening) occurring within 30 days after surgery or bronchopleural fistula within 3 months. Prolonged air leakage was defined as persisting for $>5$ days after surgery. Prolonged pleural effusion was defined as $>1.5 \mathrm{~L}$ until 5 days after surgery. Either or both predicted postoperative $\mathrm{FEV}_{1.0}$ and $\mathrm{DL}_{\mathrm{CO}}$ $<40 \%$ were defined as high-risk comorbidity. Pulmonary assessment included complete history, physical examination, and pulmonary function tests (PFTs). Predicted postoperative lung function was calculated by the segments method based on the total number of segments (42), then corrected for segments that were obstructed by tumor preoperatively [18]. In our physiological exclusion criteria, postoperative $\mathrm{FEV}_{1.0} \geq 600 \mathrm{~mL}$ was considered a prerequisite for resection. However, $\mathrm{PaCO}_{2} \leq 50$ Torr was considered a prerequisite for resection traditionally, but we did not exclude patients with only hypercapnia. This study included three patients with $\mathrm{PaCO}_{2}>50$ Torr (50.6, 50.3 
and 50.2 Torr, respectively) and all patients had postoperative $\mathrm{FEV}_{1.0} \geq 600 \mathrm{~mL}$.

\section{ABG}

The patients were divided into two groups according to the results of ABG analysis: a normal ABG group $(n=269)$ and an abnormal ABG group $(n=145)$ from a previous report [19] and our institution. The abnormal group included at least one of the following parameters: [1] $\mathrm{PaO}_{2} \leq 80$ Torr $(n=83$, median 75 , range $62-79$; [2] $\mathrm{PaCO}_{2} \leq 35$ Torr $(n=22$, median 34.0, range 31.1-34.9) or $\geq 45$ Torr $(n=50$, median 46.1 , range, $45.0-50.6)$; or [3] $\mathrm{pH} \leq 7.35(n=5$, median 7.335, range 7.332-7.349), or $\geq 7.45$ ( $n=14$, median 7.456, range 7.451-7.485).

\section{Statistical analysis}

Comparison of continuous and dichotomous variables between the two groups was performed using the Mann - Whitney U test, the $x^{2}$ test, or Fisher's exact test. The Kaplan - Meier method and log-rank test were used for survival analysis. Multivariate analysis was performed with a Cox regression model with forward stepwise selection and multivariate risk ratios with $95 \%$ confidence intervals (CIs) were calculated. $P<0.05$ was considered statistically significant. Statistical analysis was performed using JMP 10 software (SAS Institute, Cary, NC, USA).

\section{Results}

\section{Clinicopathological features}

Of these 414 patients, 302 had adenocarcinoma, 99 squamous cell carcinoma, eight adenosquamous carcinoma, and five large cell carcinoma. As to pathological stage, 232 patients were in stage IA and 182 in stage IB. Table 1 shows the clinicopathological characteristics of the two groups. The patients in the normal ABG group (median age 67 years) were significantly younger than those in the abnormal ABG group (median age 70 years) $(p=0.005$, Mann - Whitney U test). There were no significant differences in gender, body mass index, smoking history, Eastern Cooperative Oncology Group performance status (PS), Hugh-Jones ( $\mathrm{H}-\mathrm{J}$ ) classification, postoperative predicted PFTs, histology and differentiation of the resected tumor, pathological stage, tumor location, surgical procedures, blood loss, operative time, and adjuvant therapy between the two groups.

\section{Preoperative comorbidity and postoperative complications}

The postoperative course was uneventful in 281 patients and one hospital death was associated with acute exacerbation of interstitial pneumonia (IP). As shown in Table 2, there were no significant differences in preoperative comorbidity, such as any prior tumor, hypertension, diabetes mellitus, and cerebral, cardiac, renal and liver diseases, between the normal and abnormal ABG groups. The patients in the abnormal ABG group had a higher ratio of pulmonary comorbidity (chronic obstructive pulmonary disease [COPD]/IP) compared with those in the normal ABG group.

There were 16 major and 117 minor complications in the remaining 133 patients. The 16 major complications comprised: postoperative bleeding that required re-exploration/ interventional radiology in two patients; cerebral infarction in one; respiratory failure/pneumonia that required mechanical ventilation in nine (including one with acute exacerbation of interstitial pneumonia previously described); and other organ failure in four. Minor complications occurred in 117 patients. Prolonged air leakage occurred in 50 (12.1\%) and supraventricular arrhythmia in 27 (5.8 \%). There were no significant differences in postoperative complications between the normal and abnormal ABG groups.

\section{Long-term postoperative outcome}

Although ten patients (2.4\%) were lost during follow-up, no patient was lost for $\geq 2$ years. The overall mean duration of follow-up was 5.6 years (range $0.1-16.2$ years) and 2343 patient-years were detected. There were 65 deaths from lung cancer, 80 from other diseases, including 23 related to other cancers, and 269 patients were still alive, including 16 with lung cancer recurrence. In the normal ABG group $(n=269)$, there were 35 deaths from lung cancer (13\%), 47 from other diseases (17\%) and 187 patients were still alive (70 \%), whereas in the abnormal ABG group $(n=145)$, there were 30 deaths from cancer (21\%), 33 from other diseases (23\%) and 82 patients were still alive (56\%). As shown in Fig. 1, the 3-, 5- and 10year survival rates in the normal and abnormal ABG groups were 87,77 and $56 \%$, and 78, 63 and $42 \%$, respectively $(p=0.006)$. As shown in Fig. 2 , there were no significant differences in survival between those with normal versus abnormal $\mathrm{pH}(p=0.067)$, and normal versus low $\mathrm{PaO}_{2}(<80$ Torr $)(p=0.251)$. The survival rates in the high $(p=0.049)$ and low $(p<0.001) \mathrm{PaCO}_{2}$ groups were significantly lower than those in the normal $\mathrm{PaCO}_{2}$ group.

Although there were no significant differences between the two groups for cause of death $(p=0.554)$, the allcancer-related (including secondary or any prior tumors) and non-cancer-related survival rates in the abnormal ABG group were significantly poor compared with those in the normal group ( $p=0.038$ and 0.041 , respectively) as shown in Fig. 3.

\section{Multivariate analysis of $A B G$ and clinical functions}

According to the log-rank test, gender, age, PS (0-1 vs 2), ABG, postoperative predicted PFTs, histology, degree of tumor differentiation, pathological stage, postoperative complications and some preoperative comorbidity (cardiac, 
Table 1 Clinicopathological characteristics according to normal or abnormal ABGs

\begin{tabular}{|c|c|c|c|c|c|}
\hline \multirow[t]{2}{*}{ Group } & & \multirow[t]{2}{*}{ Patients } & \multirow{2}{*}{$\begin{array}{l}\text { Normal ABG } \\
(n=269)\end{array}$} & \multirow{2}{*}{$\begin{array}{l}\text { Abnormal ABG } \\
(n=145)\end{array}$} & \multirow[t]{2}{*}{$p$ value } \\
\hline & & & & & \\
\hline \multirow[t]{2}{*}{ Age (years) } & $<70$ & 233 & 164 & 69 & 0.009 \\
\hline & $\geq 70$ & 181 & 105 & 76 & \\
\hline \multirow[t]{2}{*}{ Gender } & Male & 250 & 159 & 91 & 0.469 \\
\hline & Female & 164 & 110 & 54 & \\
\hline $\mathrm{BMI}\left(\mathrm{Kg} / \mathrm{m}^{2}\right)$ & & & $22.2 \pm 3.2$ & $22.0 \pm 3.4$ & 0.539 \\
\hline \multirow[t]{2}{*}{ Smoking History } & Yes & 261 & 165 & 96 & 0.326 \\
\hline & No & 153 & 104 & 49 & \\
\hline \multirow[t]{2}{*}{ PS } & $0-1$ & 384 & 250 & 134 & 0.844 \\
\hline & 2 & 30 & 19 & 11 & \\
\hline \multirow[t]{2}{*}{$\mathrm{H}-\mathrm{J}$ classification } & $1-2$ & 401 & 261 & 140 & 0.792 \\
\hline & 3 & 13 & 8 & 5 & \\
\hline \multirow[t]{2}{*}{ Predicted post PFTs } & $\geq 40$ & 383 & 253 & 130 & 0.105 \\
\hline & $<40$ & 31 & 16 & 15 & \\
\hline \multirow[t]{3}{*}{ Histology } & $\mathrm{Ad}$ & 302 & 203 & 99 & 0.326 \\
\hline & $\mathrm{Sq}$ & 99 & 57 & 42 & \\
\hline & Others & 13 & 9 & 4 & \\
\hline \multirow[t]{2}{*}{ Differentiation } & Well & 133 & 87 & 46 & 0.898 \\
\hline & Mod/poor & 281 & 182 & 99 & \\
\hline \multirow[t]{2}{*}{ p-stage } & IA & 233 & 160 & 73 & 0.068 \\
\hline & IB & 181 & 109 & 72 & \\
\hline \multirow[t]{5}{*}{ Location } & Rt. upper & 133 & 89 & 44 & 0.815 \\
\hline & Rt. middle & 28 & 17 & 11 & \\
\hline & Rt. lower & 86 & 59 & 27 & \\
\hline & Lt. upper & 92 & 57 & 35 & \\
\hline & Lt. lower & 74 & 46 & 28 & \\
\hline \multirow[t]{2}{*}{ Surgical procedure } & Lobectomy & 405 & 265 & 140 & 0.197 \\
\hline & Bilobectomy & 9 & 4 & 5 & \\
\hline Blood loss (g) & & & $125 \pm 141$ & $137 \pm 143$ & 0.234 \\
\hline Operative time (min) & & & $192 \pm 65$ & $203 \pm 67$ & 0.483 \\
\hline \multirow[t]{2}{*}{ Adjuvant therapy } & Yes & 53 & 29 & 24 & 0.099 \\
\hline & No & 361 & 240 & 121 & \\
\hline
\end{tabular}

ad adenocarcinoma; $B M I$ body mass index; $p$-stage pathological stage; sq squamous carcinoma

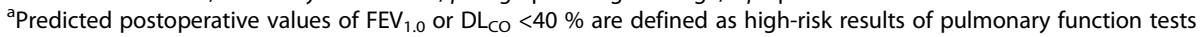

cerebral and liver disease and any prior tumor history) were significantly associated with survival, as shown in Table 3. According to multivariate analysis applying the above significant variables, gender, age, PS, histology (non-adenocarcinoma), differentiation, pathological stage, any prior tumor and ABG (risk ratio, $1.61 ; p=0.006$ ) were independent predictors of overall survival. When multivariate analysis was performed using $\mathrm{ABG}$ variables, both high $\mathrm{PaCO}_{2}$ (risk ratio, 1.84; $p=0.016$ ) and low $\mathrm{PaCO}_{2}$ (risk ratio, 1.99; $p=0.043$ ) were identified as independent factors.

\section{Discussion}

The key finding of this study is that preoperative ABG is a predictor of long-term prognosis in stage I NSCLC, independent of other important determinants such as age, gender, PS and pathological stage. $\mathrm{H}-\mathrm{J}$ classification, predicted postoperative PFTs, and cardiac/cerebral disease, which are considered important physiological factors, were not independent prognostic factors according to multivariate analysis.

To select a subgroup of patients with stage I disease that might benefit from adjuvant therapy, many investigators 
Table 2 Preoperative comorbidity and postoperative complications according to normal or abnormal ABGs

\begin{tabular}{|c|c|c|c|c|}
\hline Group & Patients & $\begin{array}{l}\text { Normal ABG } \\
(n=269)\end{array}$ & $\begin{array}{l}\text { Abnormal ABG } \\
(n=145)\end{array}$ & $p$ value \\
\hline \multicolumn{5}{|l|}{ Preoperative comorbidities } \\
\hline Hypertension & 105 & 63 & 42 & 0.216 \\
\hline Diabetes mellitus & 61 & 37 & 24 & 0.444 \\
\hline Cerebral disease & 36 & 20 & 16 & 0.215 \\
\hline Cardiovascular disease & 53 & 32 & 21 & 0.459 \\
\hline COPD/IP & 64 & 32 & 32 & 0.006 \\
\hline Moderate-to-sever renal disease ${ }^{a)}$ & 84 & 55 & 29 & 0.914 \\
\hline Child-Pugh classification (B or C) & 9 & 7 & 2 & 0.416 \\
\hline Any prior tumor & 96 & 63 & 33 & 0.879 \\
\hline \multicolumn{5}{|l|}{ Postoperative complications } \\
\hline In-hospital mortality & 1 & 0 & 1 & \\
\hline Major complications & 16 & 10 & 6 & 0.832 \\
\hline Re-exploration/IVR & 2 & 1 & 1 & \\
\hline Bronchopleural fistula & 0 & 0 & 0 & \\
\hline Cerebral infarction & 1 & 1 & 0 & \\
\hline Respiratory failure/pneumonia & 9 & 5 & 4 & \\
\hline Other organ failure ${ }^{b)}$ & 4 & 3 & 1 & \\
\hline Minor complications & 117 & 83 & 34 & 0.110 \\
\hline Continuous air leakage & 50 & 34 & 16 & 0.633 \\
\hline Prolonged pleural effusion/chylothorax & 31 & 21 & 10 & 0.737 \\
\hline Supraventricular arrhythmias & 27 & 20 & 7 & 0.820 \\
\hline Atelectasis/obstructive symptoms & 12 & 9 & 3 & 0.461 \\
\hline Wound/intrathoracic infection & 11 & 7 & 4 & 0.925 \\
\hline Change in mental status & 8 & 7 & 1 & 0.178 \\
\hline Paresis of recurrent laryngeal nerve & 4 & 2 & 2 & 0.528 \\
\hline
\end{tabular}

IVR, inverse ratio ventilation

${ }^{a}$ Moderate-to-severe renal disease was defined as estimated glomerular filtration rate $<60 \mathrm{~mL} / \mathrm{min} / 1.73 \mathrm{~m}^{2}$

b Including cardiac, renal and liver failure

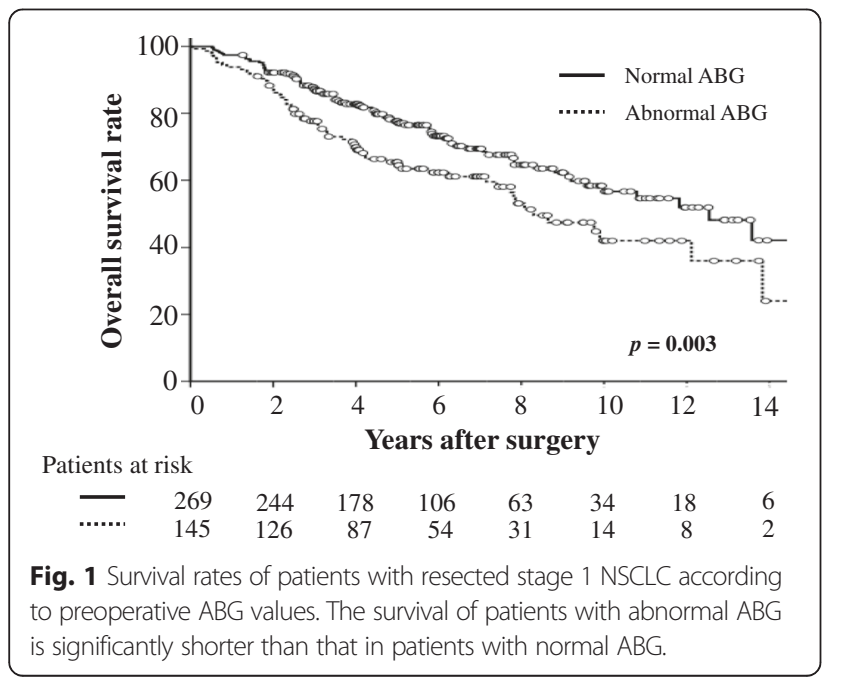

have attempted to identify pathological prognostic factors. These attempts have included analysis of histological subtype, size of primary tumor, degree of tumor differentiation, tumor markers, and lymphatic or vascular invasion [20, 21]. Recent studies have reported that the following molecular markers are associated with poor prognosis or recurrence in stage I NSCLC: cell cycle regulation/apoptosis, angiogenesis, growth regulation, cellular adhesion, cell cycle regulation, and basement membrane invasion [20, 22]. As for physiological factors, age, gender, PS, weight loss, depressed mood, quality of life, smoking [20], Charlson Comorbidity Index score [23], $\mathrm{FEV}_{1.0} / \mathrm{DL}_{\mathrm{CO}}[8-10]$ have been reported as long-term prognostic factors in patients undergoing pulmonary resection. The Charlson Comorbidity Index allots weighted scores based on the relative mortality risk to 19 factors that were found to significantly influence survival in the study subjects [23, 24]. Although these 19 factors include 

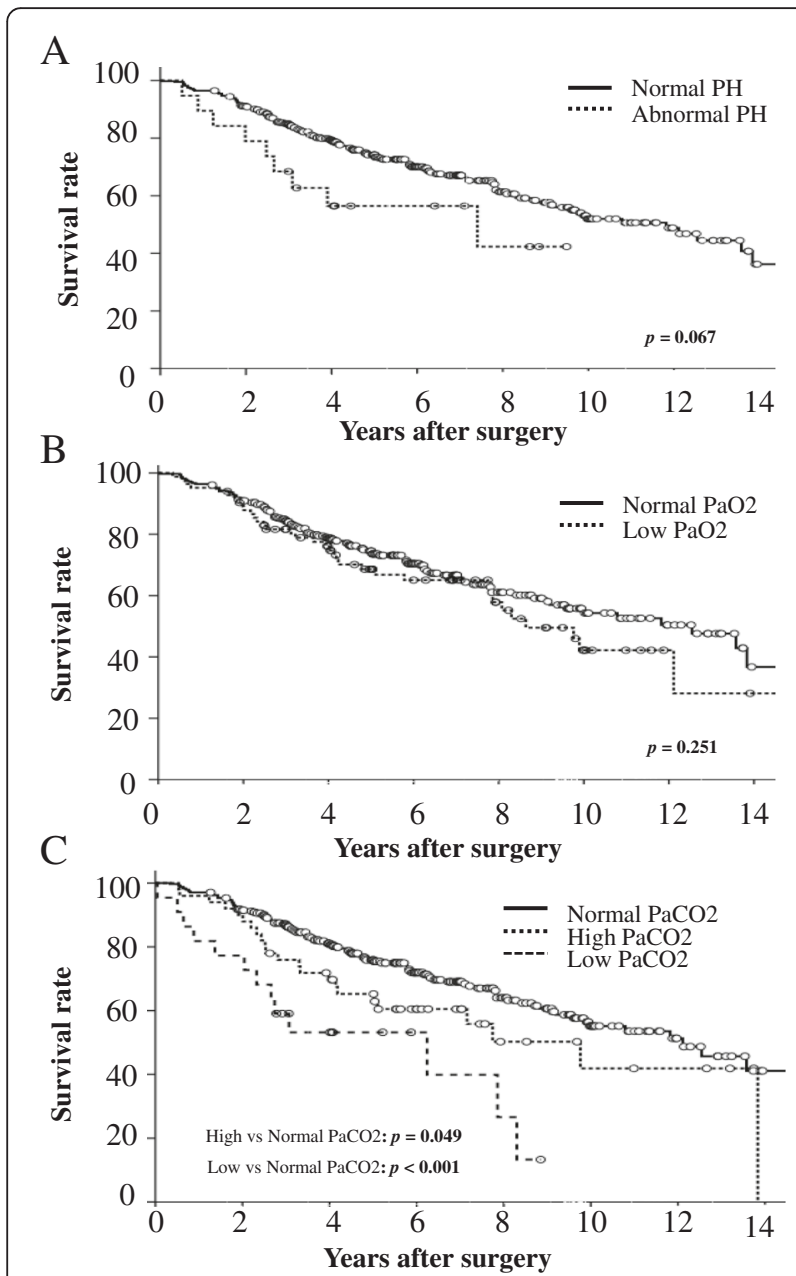

Fig. 2 Overall survival of patients with stage 1 NSCLC according to preoperative $A B G$ values: (a) $\mathrm{pH}$, (b) $\mathrm{PaO}_{2}$ and (c) $\mathrm{PaCO}_{2}$

some such as heart failure, chronic pulmonary disease and renal disease that could affect ABG, abnormal ABG was not identified as a prognostic comorbidity factor in that study.

The preoperative physiological assessment of a patient being considered for surgical resection of lung cancer must take into account the immediate perioperative risks from comorbid cardiopulmonary disease, the long-term risks of pulmonary disability, and the threat to survival posed by inadequately treated lung cancer. As is evident in recently published algorithms, selection based on physiological variables of patients for major pulmonary resection for NSCLC currently focuses on perioperative outcomes [5]. Many authors have assessed physiological prognostic factors in patients with NSCLC and focused on PFTs, mainly preoperative or predicted postoperative $\mathrm{FEV}_{1}$ and $\mathrm{DL}_{\mathrm{CO}}$ [7-10, 25-27]. Predicted postoperative pulmonary function can be theoretically determined by the amount of parenchymal resection. However, various factors can also influence it, including site of resection
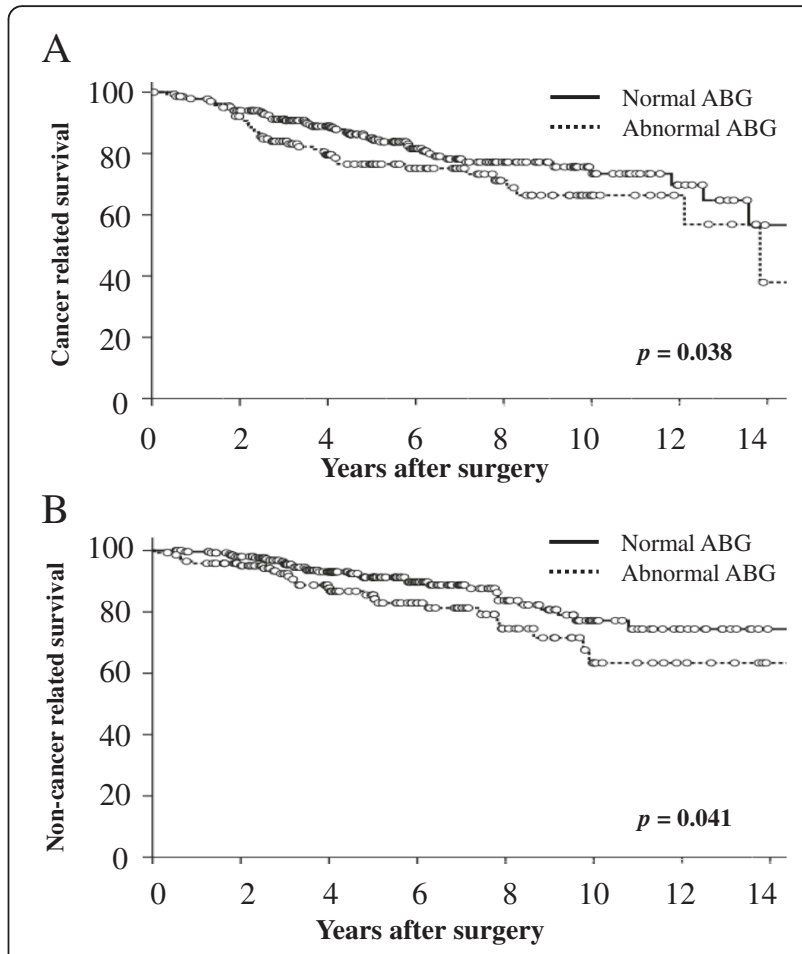

Fig. 3 Overall survival based on cause of death in patients with stage 1 NSCLC according to preoperative ABG values: (a) all-cancer-related and (b) non-cancer-related survival rates

(upper or lower lobectomy), severity of pulmonary emphysema/fibrosis, the surgical approach (open or videoassisted thoracic surgery), and chemotherapy/radiation therapy [26]. When multivariate analysis was performed excluding $\mathrm{ABG}$, predicted postoperative $\mathrm{FEV}_{1.0}$ and $\mathrm{DL}_{\mathrm{CO}}$ (shown as predicted PFT) was an independent prognostic marker (risk ratio, 1.79, $95 \% \mathrm{CI}, 1.01-3.02 ; p=0.047$ ) in this study.

Abnormal ABG in patients with lung cancer undergoing surgical resection is reportedly a comorbidity risk factor (mainly respiratory disorder) $[5,11,12]$. However, this is controversial because two series have reported that perioperative complications are not more numerous in patients with preoperative hypercapnia [25, 28]. In the present study, we also found no significant difference in postoperative complications, including respiratory failure, between patients with preoperative $\mathrm{CO}_{2}$ in the normal range and those with hypercapnia. When multivariate analysis was performed using three $A B G$ variables as for physiological factors, both high and low $\mathrm{PaCO}_{2}$ were identified as independent factors and further, larger studies are necessary to clarify these findings.

We did not routinely measure postoperative ABG in patients without complications, therefore preoperative or short-term changes in $\mathrm{PaO}_{2}$ or $\mathrm{PaCO}_{2}$ are unclear. In a previous study, although small decreases in $\mathrm{PaO}_{2}$ were detected after pneumonectomy, there were no significant 
Table 3 Results of survival analysis

\begin{tabular}{|c|c|c|c|c|}
\hline Factors & $\begin{array}{l}\text { Univariate } \\
\text { ( } p \text { value) }\end{array}$ & $\begin{array}{l}\text { Multivariate } \\
\text { ( } p \text { value) }\end{array}$ & Risk ratio & $95 \% \mathrm{Cl}$ \\
\hline Gender (Male vs Female) & $<0.001$ & $<0.001$ & 2.40 & $1.55-3.81$ \\
\hline Age ( $\geq 70$ years) & $<0.001$ & $<0.001$ & 2.55 & $1.78-3.69$ \\
\hline PS (2 vs. 0-1) & $<0.001$ & 0.036 & 1.85 & $1.04-3.09$ \\
\hline H-J classification (3 vs. 1-2) & 0.070 & - & - & - \\
\hline Smoking & 0.001 & 0.487 & - & - \\
\hline ABG (Abnormal vs. Normal) & 0.002 & 0.006 & 1.61 & $1.14-2.26$ \\
\hline Predicted post $\mathrm{PFT}^{\mathrm{a})}$ & 0.016 & 0.059 & - & - \\
\hline Histology (others vs. Ad) & 0.017 & 0.011 & 1.65 & $1.12-2.44$ \\
\hline Differentiation (m/p vs well) & $<0.001$ & 0.014 & 1.71 & $1.11-2.71$ \\
\hline p-Stage (IB vs IA) & $<0.001$ & 0.002 & 1.74 & $1.23-2.48$ \\
\hline Operative procedures ${ }^{\mathrm{b})}$ & 0.470 & - & - & - \\
\hline Location & 0.268 & - & - & - \\
\hline Postoperative complication & 0.017 & 0.320 & - & - \\
\hline Adjuvant therapy & 0.629 & - & - & - \\
\hline \multicolumn{5}{|l|}{ Preoperative comorbidities } \\
\hline Hypertension & 0.533 & - & - & - \\
\hline Diabetes mellitus & 0.652 & - & - & - \\
\hline $\operatorname{eGFR}\left(<60 \mathrm{ml} / \mathrm{min} / 1.73 \mathrm{~m}^{2}\right)$ & 0.078 & - & - & - \\
\hline Child-Pugh classification (B or C) & 0.031 & 0.389 & - & - \\
\hline Cardiac disease & 0.011 & 0.241 & - & - \\
\hline Cerebral disease & 0.010 & 0.594 & - & - \\
\hline Any prior tumors & $<0.001$ & $<0.001$ & 3.49 & $2.37-5.10$ \\
\hline
\end{tabular}

eGFR estimated glomerular filtration rate; $\mathrm{m} / \mathrm{p}$ moderate or poorly

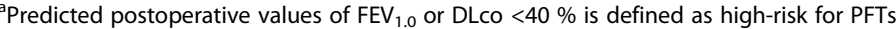

boperative procedures, lobectomy versus more than lobectomy

decreases in $\mathrm{PaO}_{2}$ after minor resection (including lobectomy) and no significant changes in $\mathrm{PaCO}_{2}$ after any type of resection [27]. Low $\mathrm{PaO}_{2}$ ( $<80$ Torr) was not a comorbidity predictor of prognosis in patients with early lung cancer undergoing pulmonary resection (Fig. $2 \mathrm{~b}, p=0.251$ ). This may be of interest regarding home oxygen therapy.

We postulated that patients with abnormal ABGs might have poor prognosis because of the increased risk of non-cancer-specific death. It is important to note that deaths from both cancer and other causes were higher in the abnormal ABG group. It is possible that abnormal ABGs might affect or be affected by cancer biology, and further, larger studies are necessary to clarify our findings and determine whether this trend is significant.

\section{Conclusion}

In the present study, we found that preoperative ABGs, not only hypercapnia but also hypocapnia are predictors of long-term prognosis in stage I NSCLC. Surgical strategies for patients with abnormal ABG values should be planned considering not only immediate or short-term risk, which relates to perioperative morbidity and mortality, but also long-term survival risk.

\section{Abbreviations \\ ABG: arterial blood gas; $\mathrm{DL}_{\mathrm{co}}$ : diffusion capacity of the lungs for $\mathrm{CO}$; \\ $\mathrm{FEV}_{1.0}$ : forced expiratory volume in 1 second; $\mathrm{H}-\mathrm{J}$ classification: Hugh-Jones classification; NSCLC: non-small cell lung cancer; $\mathrm{PaCO}_{2}$ : partial pressure of $\mathrm{CO}_{2}$ in arterial blood; $\mathrm{PaO}_{2}$ : partial pressure of oxygen in arterial blood; \\ PFTs: pulmonary function tests; PS: performance status; $\mathrm{SaO}_{2}$ : oxygen saturation.}

\section{Competing interests}

The authors declare that they have no competing interests.

\section{Authors' contributions}

All authors were involved in the preparation of this manuscript. SM performed statistical analysis, wrote and revised the manuscript. NN and SM designed the study. SM, TI, NI, TT, SH, HK and NN performed the operation and participated in collecting the data. All authors read and approved the final manuscript.

Received: 31 July 2015 Accepted: 7 January 2016

Published online: 13 January 2016

References

1. Sawabata N, Miyaoka E, Asamura H, Nakanishi Y, Eguchi K, Mori M, et al. Japanese lung cancer registry study of 11,663 surgical cases in 2004: demographic and prognosis changes over decade. J Thorac Oncol. 2011;6(7):1229-35. 
2. Motohiro A, Ueda H, Komatsu H, Yanai N, Mori T. Cancer NCHSGfL. Prognosis of non-surgically treated, clinical stage I lung cancer patients in Japan. Lung Cancer. 2002;36(1):65-9.

3. Onishi $H$, Shirato $H$, Nagata $Y$, Hiraoka M, Fujino M, Gomi K, et al. Stereotactic body radiotherapy (SBRT) for operable stage I non-small-cell lung cancer: can SBRT be comparable to surgery? Int J Radiat Oncol Biol Phys. 2011;81(5):1352-8.

4. Colice GL, Shafazand S, Griffin JP, Keenan R, Bolliger CT. Physicians ACoC Physiologic evaluation of the patient with lung cancer being considered for resectional surgery: ACCP evidenced-based clinical practice guidelines (2nd edition). Chest. 2007;132(3 Suppl):161S-77S.

5. Brunelli A, Kim AW, Berger Kl, Addrizzo-Harris DJ. Physiologic evaluation of the patient with lung cancer being considered for resectional surgery: Diagnosis and management of lung cancer, 3rd ed: American College of Chest Physicians evidence-based clinical practice guidelines. Chest. 2013;143(5 Suppl):e166S-90S

6. Mazzone PJ. Preoperative evaluation of the lung cancer resection candidate Expert Rev Respir Med. 2010;4(1):97-113

7. Baser S, Shannon VR, Eapen GA, Jimenez CA, Onn A, Keus L, et al. Pulmonary dysfunction as a major cause of inoperability among patients with non-small-cell lung cancer. Clin Lung Cancer. 2006;7(5):344-9.

8. Ferguson MK, Watson S, Johnson E, Vigneswaran WT. Predicted postoperative lung function is associated with all-cause long-term mortality after major lung resection for cancer. Eur J Cardiothorac Surg. 2014;45(4): 660-4.

9. Pompili C, Brunelli A, Xiumé F, Refai M, Salati M, Sabbatini A. Predictors of postoperative decline in quality of life after major lung resections. Eur J Cardiothorac Surg. 2011:39(5):732-7.

10. Win T, Sharples L, Wells FC, Ritchie AJ, Munday H, Laroche CM. Effect of lung cancer surgery on quality of life. Thorax. 2005;60(3):234-8.

11. Celli BR. What is the value of preoperative pulmonary function testing? Med Clin North Am. 1993;77(2):309-25.

12. Zibrak JD, O'Donnell CR, Marton K. Indications for pulmonary function testing. Ann Intern Med. 1990;112(10):763-71.

13. Armstrong P, Congleton J, Fountain SW, Jaboe T, McAuley DF, MacMahon J, et al. BTS guidelines: Guidelines on the selection of patients with lung cancer for surgery. British Thoracic Society andSociety of Cardiothoracic Surgeons of Great Britain and Ireland Working Party. Thorax. 2001:56:89-108.

14. Mountain CF. Revisions in the International System for Staging Lung Cancer. Chest. 1997:111(6):1710-7.

15. Brambilla E, Travis WD, Colby TV, Corrin B, Shimosato Y. The new World Health Organization classification of lung tumours. Eur Respir J. 2001;18(6):1059-68

16. Detterbeck FC, Boffa DJ, Tanoue LT. The new lung cancer staging system. Chest. 2009;136(1):260-71.

17. Travis WD, Giroux DJ, Chansky K, Crowley J, Asamura H, Brambilla E, et al. The IASLC Lung Cancer Staging Project: proposals for the inclusion of broncho-pulmonary carcinoid tumors in the forthcoming (seventh) edition of the TNM Classification for Lung Cancer. J Thorac Oncol. 2008;3(11):1213-23.

18. Nakahara K, Monden Y, Ohno K, Miyoshi S, Maeda H, Kawashima Y. A method for predicting postoperative lung function and its relation to postoperative complications in patients with lung cancer. Ann Thorac Surg. 1985;39(3):260-5.

19. Singh V, Khatana S, Gupta P. Blood gas analysis for bedside diagnosis. Natl J Maxillofac Surg 2013;4(2):136-41.

20. Brundage MD, Davies D, Mackillop WJ. Prognostic factors in non-small cell lung cancer: a decade of progress. Chest. 2002:122(3):1037-57.

21. Mizuguchi S, Nishiyama N, Iwata T, Nishida T, Izumi N, Tsukioka T, et al. Serum Sialyl Lewis $x$ and cytokeratin 19 fragment as predictive factors for recurrence in patients with stage I non-small cell lung cancer. Lung Cancer. 2007:58(3):369-75

22. D'Amico TA, Aloia TA, Moore MB, Conlon DH, Herndon JE, Kinch MS, et al. Predicting the sites of metastases from lung cancer using molecular biologic markers. Ann Thorac Surg. 2001;72(4):1144-8.

23. Moro-Sibilot D, Aubert A, Diab S, Lantuejoul S, Fourneret $P$, Brambilla E, et al. Comorbidities and Charlson score in resected stage I nonsmall cell lung cancer. Eur Respir J. 2005;26(3):480-6.

24. Charlson ME, Pompei P, Ales KL, MacKenzie CR. A new method of classifying prognostic comorbidity in longitudinal studies: development and validation. J Chronic Dis. 1987:40(5):373-83.
25. Kearney DJ, Lee TH, Reilly JJ, DeCamp MM, Sugarbaker DJ. Assessment of operative risk in patients undergoing lung resection. Importance of predicted pulmonary function. Chest. 1994;105(3):753-9.

26. Ueda K, Hayashi M, Tanaka N, Tanaka T, Hamano K. Long-term pulmonary function after major lung resection. Gen Thorac Cardiovasc Surg. 2014;62(1):24-30.

27. Pierce RJ, Copland JM, Sharpe K, Barter CE. Preoperative risk evaluation for lung cancer resection: predicted postoperative product as a predictor of surgical mortality. Am J Respir Crit Care Med. 1994;150(4):947-55.

28. Harpole DH, Liptay MJ, DeCamp MM, Mentzer SJ, Swanson SJ, Sugarbaker DJ. Prospective analysis of pneumonectomy: risk factors for major morbidity and cardiac dysrhythmias. Ann Thorac Surg. 1996;61(3):977-82.

\section{Submit your next manuscript to BioMed Central and we will help you at every step:}

- We accept pre-submission inquiries

- Our selector tool helps you to find the most relevant journal

- We provide round the clock customer support

- Convenient online submission

- Thorough peer review

- Inclusion in PubMed and all major indexing services

- Maximum visibility for your research

Submit your manuscript at www.biomedcentral.com/submit
) Biomed Central 